\title{
Comparative Phytochemical Analyses of Resins of Boswellia Species (B. papyrifera (Del.) Hochst., B. neglecta S. Moore, and $B$. rivae Engl.) from Northwestern, Southern, and Southeastern Ethiopia
}

\author{
Deribachew Bekana, ${ }^{1}$ Tesfahun Kebede, ${ }^{1}$ Mulugeta Assefa, ${ }^{1}$ and Habtemariam Kassa ${ }^{2}$ \\ ${ }^{1}$ Department of Chemistry, College of Natural and Computational Sciences, Haramaya University, P.O. Box 138, Dire Dawa, Ethiopia \\ ${ }^{2}$ Centre for International Forestry Research, Ethiopia Office, P.O. Box 5689, Addis Ababa, Ethiopia
}

Correspondence should be addressed to Deribachew Bekana; gado430@yahoo.com

Received 2 September 2013; Accepted 11 November 2013; Published 13 February 2014

Academic Editors: A. Bouklouze, A. Garcia Asuero, and R. N. Rao

Copyright (C) 2014 Deribachew Bekana et al. This is an open access article distributed under the Creative Commons Attribution License, which permits unrestricted use, distribution, and reproduction in any medium, provided the original work is properly cited.

\begin{abstract}
Oleogum resins of $B$. papyrifera, $B$. neglecta, and B. rivae were collected from northwestern, southern, and southeastern Ethiopia, and their respective methanol extracts and essential oils were extracted and analyzed by gas chromatography (GC) and gas chromatography-mass spectrometry (GC-MS). The investigation on essential oils led to the identification of 6 , 7, and 8 constituents for B. papyrifera, B. neglecta, and B. rivae, respectively. The essential oil of B. papyrifera is mainly characterized by the presence of octyl acetate (57.1-65.7\%) and n-octanol (3.4-8.8\%). B. neglecta is rich in $\alpha$-pinene (32.6-50.7\%) followed by terpinen-4-ol (17.5$29.9 \%)$ and $\alpha$-thujene (12.7-16.5\%), whereas B. rivae was predominated by $\alpha$-pinene (32.5-66.2\%) followed by p-cymene (5.7-21.1\%) and limonene (1.1-19.6\%). Methanol extracts of the three Boswellia species were found to consist of diterpines (incensole, incensyl acetate and verticilla-4(20),7,11-triene), triterpenes ( $\beta$-amyrin, $\alpha$-amyrin, $\beta$-amyrenone, and $\alpha$-amyrenone), nortriterpenes (24noroleana-3,12-diene and 24-norursa-3,12-diene), and $\alpha$-boswellic acid. The investigation on the methanol extract showed that only B. papyrifera contains diterpenes and nortriterpenes, whereas B. rivae and B. neglecta consist of only triterpenes. The results indicate that the three Boswellia species were characterized by some terpenes and these terpenoic constituents could be recognized as chemotaxonomical markers for each species.
\end{abstract}

\section{Introduction}

The family Burseraceae is represented by 17 genera and 500600 species, widespread in tropical and subtropical regions. The genus Boswellia has about 25 species of small trees and shrubs occurring in dry land regions from west Africa to Arabia and from south to northeast Tanzania, in India, and one species in Madagascar. The genus is centered in northeast Africa where about $75 \%$ of the species are endemic to the area. They are trees or shrubs often with latex, resins, or oils which are strongly aromatic $[1,2]$.

Frankincense, gum olibanum, or olibanum are the common names given to the oleogum resin which is obtained through incisions made in the trunks of trees of the genus Boswellia (family Burseraceae). It is plant product and belongs to a group of aromatic gums and resins which contain odiferous substances [2-4].

Frankincense consists of essential oils, gum, and terpenoids [5]. It is a complex of $30-60 \%$ alcohol soluble resins (diterpenes, triterpenes), 5-10\% essential oil, which is soluble in organic solvents, and the rest is made up of polysaccharides (gum), which are soluble in water [2]. Its essential oil portion is composed of ester $(62.1 \%)$, alcohol (15.4\%), monoterpene hydrocarbons (9.9\%), diterpenes (7.1\%) [6], and sesquiterpenes. Gum fraction is composed of pentose and hexose sugar and resin portion is mainly composed of pentacyclic triterpene acid of which boswellic acid is the active moiety [7]. Mono- and sesquiterpenes are highly volatile compounds, diterpenes exhibit low volatility, 
triterpenes exhibit very low volatility, and polysaccharides are not volatile [8].

Different commercial varieties of frankincense can be distinguished by the chemical constituents of their essential oil. The constituents of the essential oil of frankincense were first investigated by Stenhouse [9] and he identified fourteen monoterpenoic constituents. Chemical investigation by Basar [2] on the essential oil of $B$. neglecta and $B$. rivae led to isolation and identification of monoterpenes. The major compounds identified in B. neglecta were $\alpha$-thujene (21.3\%), $\alpha$-pinene $(21.3 \%)$, sabinene (1.3\%), $\Delta$-3-carene (1.9\%), pcymene (11.8\%), terpinen-4-ol (5.3\%), and verbenone (2.1\%). $B$. rivae resin oil composition is quite similar to that of $B$. neglecta which consists of cara-2,4-diene (1.8\%), $\alpha$ thujene (2.9\%), $\alpha$-pinene (16.7\%), o-cymene (3.9\%), $\Delta-3$ carene (17.3\%), p-cymene (3.2\%), and limonene (21.1\%). In the study, triterpenoic constituents, namely, $\alpha$-amyrin (9.1\%), $\beta$-amyrin (0.7\%), epi- $\alpha$-amyrin (1.6\%), $\beta$-amyrenone (1.4\%), $\alpha$ - and $\beta$-amyrin (3-,12-dien- $\alpha$-amyrin (3.4\%), and 3-,12dien- $\beta$-amyrin (1.1\%), were also identified from pyrolysate of B. neglecta. Similarly, 24-norursa-3,12-diene (18.7\%), $\alpha$ amyrin (4.2\%), $\beta$-amyrin (0.9\%), $\alpha$-amyrenone $(2.8 \%), \beta$ amyrenone $(2.3 \%)$, and epi- $\beta$-amyrin $(0.9 \%)$ were detected in the pyrolysate of $B$. rivae. Dekebo et al. [10] reported the essential oil constituents of the resin of B. papyrifera and identified $n$-hexyl acetate (1\%), $\alpha$-pinene (2.6\%), limonene (6.5\%), n-octanol (8.0\%), linalool (3.2\%), octyl acetate (56\%), caryophyllene oxide (21\%), and $\beta$-elemene (29\%).

Although Ethiopia is one of the few countries that are endowed with large frankincense resources, little proper exploitation of this resource has been made so far (i.e., the export market from Ethiopia has been weakened) due to inconsistent supply and ambiguity of grades [11]. Of the three Boswellia species found in Ethiopia, frankincense resin obtained from $B$. papyrifera is the most widely traded frankincense accounting for over $90 \%$ of the natural gum exported. The frankincense obtained from $B$. rivae and B. neglecta species is yet not of export standard [12]. As reported by Assefa et al. [13] basis for selection of export item and the respective price quotations need to be revised to reflect contents of ingredients sought after by buyers. Ethiopia will be more benefited from the export of these items provided efforts are made to develop these resources more than the current situation. However, there is paucity of information on chemical quality variations between the export standard frankincense (B. papyrifera) and the other two Boswellia species ( $B$. rivae and B. neglecta) which are not of export standard. This study is, therefore, initiated for comparative purpose, where essential oil and methanol extract composition of one species were contrasted with the other(s) to characterize the chemical classes of constituents present and to find chemotaxonomical markers, among these constituents, for the three Boswellia species.

\section{Materials and Methods}

2.1. Description of Sampling Sites and Sample Collection. The resin samples of frankincense (Boswellia species) used for this study were collected in August 2011 from northwestern and southeastern Ethiopia. From northwestern Ethiopia, three sites were selected: Metema from Amhara region, Humera from Tigray regional state, and Metekel from Benishangul Gumuz regional state. From these sites, exudates were collected from B. papyrifera. Samples from southeastern part of the country were collected from three districts, namely, Mega, Dubuluk, and Wachile from Borana zone of Oromiya region. In these entire three sites, one dominant species known as $B$. neglecta is widely grown. Then samples were also collected from Filtu, Chereti, and Dolo Odo districts of Somalia regional state. In these sites, B. rivae was dominant. The studied samples were an authentic sample which are certified for their authenticity by Agricultural Department of the Ethiopian Government Natural Gum Processing and Marketing Enterprise. The geographical locations of the districts are given in Table 1.

2.2. Chemicals and Reagents. All chemicals and reagents used were of analytical grade. Chloroform (99.9\%) and methanol (99.8\%) were purchased from Merck (Darmstadt, Germany). Anhydrous sodium sulfate was purchased from Fluka (Buchs, Switzerland).

2.3. Equipment and Instruments. Polyethylene plastic bags, ceramic mortar and pestle (Haldenwanger, Germany), a digital analytical balance (Mettler Toledo, Model AG 204, Switzerland), round bottom flask (Mumbai, India), Clevenger apparatus (Rac, India), rotary evaporator and heating mantle (Buchi, Switzerland), Gas chromatography (Monza, Italy), Gas chromatography-mass spectrometry (PerkinElmer, USA), and syringes (Hamilton Bonaduz AG, Switzerland) are among the equipment and instruments that were used in the study.

2.4. Methanol Extraction and Isolation of Essential Oils. The resins of the three Boswellia species were air-dried at room temperature for 4 weeks, grinded and homogenized to a uniform powder by ceramic mortar and pestle, and sieved. Two grams of grinded and homogenized resins powder was extracted with $30 \mathrm{~mL}$ of methanol at room temperature. The extracts were concentrated using a rotary evaporator and analyzed by GC-MS. For essential oils, the ground resins of the three Boswellia species: B. papyrifera, B. neglecta, and $B$. rivae were submitted for $3 \mathrm{~h}$ to hydrodistillation using a Clevenger-type apparatus. The obtained oils were allowed to dry over anhydrous sodium sulphate. After filtration, the oils were stored at $+4^{\circ} \mathrm{C}$ until analyzed [4].

2.5. Gas Chromatography. GC analyses were performed on Dani model 1000 Gas chromatography (Monza, Italy) equipped with flame ionization detector (FID). The analysis was carried out on a fused silica capillary column coated with HP-5 column length $30 \mathrm{~m}$, internal diameter $0.32 \mathrm{~mm}$, film thickness 0.25 micron, and 5\% phenyl 95\% methyl polysiloxane as stationary phase. The oven was programmed at 50 $210^{\circ} \mathrm{C}$ at a rate of $3^{\circ} \mathrm{C} / \mathrm{min}$ using $\mathrm{N}_{2}$ as carrier gas; injector and detector (FID) temperatures were $210^{\circ} \mathrm{C}$ and $260^{\circ} \mathrm{C}$, 
TABLE 1: Geographical locations of the study areas.

\begin{tabular}{lcc}
\hline Region & Areas & Latitude and longitude \\
\hline \multirow{4}{*}{ Northwestern } & Metema & $12^{\circ} 58^{\prime} 42.80^{\prime \prime} \mathrm{N} 36^{\circ} 09^{\prime} 54.30^{\prime \prime} \mathrm{E}$ \\
& Metekel & $1046^{\prime} 49.04^{\prime \prime} \mathrm{N} 35^{\circ} 33^{\prime} 56.83^{\prime \prime} \mathrm{E}$ \\
& Humera & $10^{\circ} 46^{\prime} 49.04^{\prime \prime} \mathrm{N} 35^{\circ} 33^{\prime} 56.83^{\prime \prime} \mathrm{E}$ \\
\hline \multirow{3}{*}{ Southeastern } & Wachile & $4^{\circ} 32^{\prime} 34.61^{\prime \prime} \mathrm{N} 39^{\circ} 04^{\prime} 06.50^{\prime \prime} \mathrm{E}$ \\
& Dubuluk & $4^{\circ} 21^{\prime} 43.22^{\prime \prime} \mathrm{N} 38^{\circ} 16^{\prime} 17.80^{\prime \prime} \mathrm{E}$ \\
& Mega & $4^{\circ} 03^{\prime} 25.06^{\prime \prime} \mathrm{N} 38^{\circ} 18^{\prime} 41.58^{\prime \prime} \mathrm{E}$ \\
\hline \multirow{3}{*}{ Eastern } & Filtu & $5^{\circ} 05^{\prime} 35.35^{\prime \prime} \mathrm{N} 40^{\circ} 39^{\prime} 30.99^{\prime \prime} \mathrm{E}$ \\
& Dolo Odo & $4^{\circ} 20^{\prime} 45.50^{\prime \prime} \mathrm{N} 42^{\circ} 12^{\prime} 82.20^{\prime \prime} \mathrm{E}$ \\
& Chereti & $5^{\circ} 21^{\prime} 57.08^{\prime \prime} \mathrm{N} 41^{\circ} 49^{\prime} 41.51^{\prime \prime} \mathrm{E}$ \\
\hline
\end{tabular}

TABLE 2: Chemical compositions (\%) of essential oils of three B. neglecta resins.

\begin{tabular}{lcccc}
\hline Retention time (min) & Components & $\begin{array}{c}\text { Dubuluk } \\
\%\end{array}$ & $\begin{array}{c}\text { Mega } \\
\%\end{array}$ & $\begin{array}{c}\text { Wachile } \\
\%\end{array}$ \\
\hline 6.4 & $\alpha$-Thujene & 16.5 & 13.0 & 12.7 \\
6.7 & $\alpha$-Pinene & 42.0 & 32.6 & 50.7 \\
7.8 & $\beta$-Pinene & 1.1 & 1.4 & 1.5 \\
8.8 & Sabinene & 0.7 & 2.9 & 1.4 \\
9.4 & p-Cymene & 2.0 & 5.1 & 2.2 \\
14.6 & Terpinen-4-ol & 28.2 & 29.9 & 17.5 \\
15.0 & Verbenone & 3.6 & 2.5 & 6.6 \\
\hline
\end{tabular}

${ }^{*}$ Components identified from the essential oil of same sample reported in our previous study [13].

respectively. Calculation of peak area percentage was performed on basis of the FID signal using the GC HPChemstation software (Agilent Technologies).

2.6. Gas Chromatography-Mass Spectrometry. GC-MS analyses were performed using a 500 series PerkinElmer Clarus GC coupled with Perkin Elmer Clarus MS quadrupole analyzer mass spectrometer at $70 \mathrm{eV}$. Fused silica capillary column type was DB-17 (30 $\mathrm{m} \times 0.25 \mathrm{~mm}$ i.d.) and the oven temperature was programmed at $80-280^{\circ} \mathrm{C}$ at a rate of $10^{\circ} \mathrm{C} / \mathrm{min}$ using helium as carrier gas; injector and detector (FID) temperatures were both maintained at $250^{\circ} \mathrm{C}$. The constituents were identified by matching their $70 \mathrm{eV}$ mass spectra with NIST Wiley databases and user generated mass spectral libraries, by comparing their corresponding retention time $\left(t_{R}\right)$ on the chromatogram, by interpretation of the mass spectra fragmentation data, and by comparison of the mass spectra obtained with those of the published literature data $[2,10,14-$ 19].

\section{Results and Discussion}

3.1. Chemical Compositions of the Essential Oils. The essential oils of the resins of B. neglecta, B. rivae, and B. papyrifera were obtained by hydrodistillation. The essential oils obtained as such were analyzed by GC and their corresponding results (chromatograms) are presented subsequently in Figures 1, 2, and 3 and Tables 2, 3, and 4 .

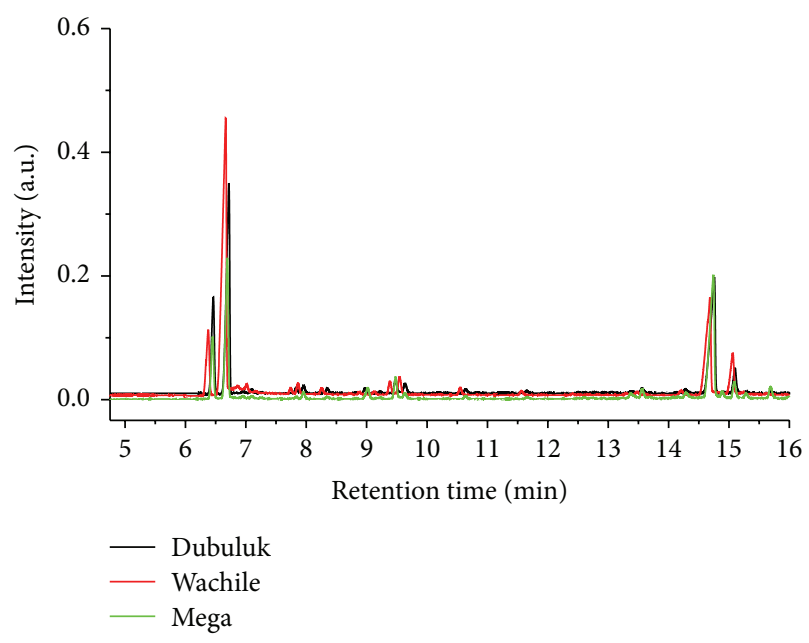

FIGURE 1: Comparison of chromatogram of essential oil of three $B$. neglecta resins.

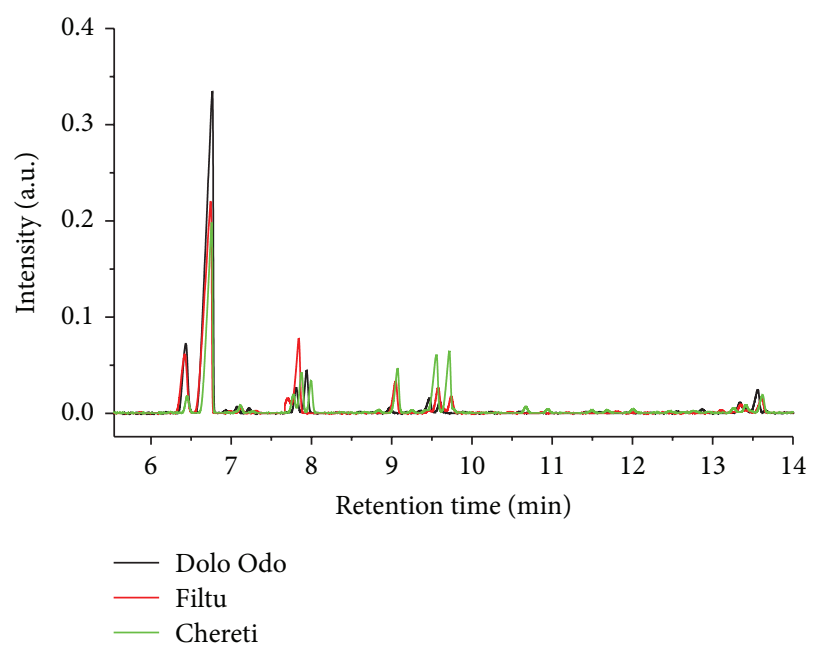

FIGURE 2: Comparison of chromatogram of essential oil of three $B$. rivae resins.

3.2. Chemical Composition of the Methanol Extracts. Frankincense is a complex mixture of essential oils and alcohol soluble resins, and the remaining are water-soluble gums which are polysaccharides. In this study, chemical compositions of methanol extract of resins of the three Boswellia species were investigated by GC-MS and their corresponding chromatograms are presented in Figures 4-8.

The chromatogram (Figure 4) for the methanol extract of resin of $B$. neglecta collected from Wachile area revealed one monoterpene: $\alpha$-pinene and three triterpenoic constituents: $\beta$-amyrenone, $\alpha$-amyrenone, and $\alpha$-amyrin. The first peak which appeared at $6.33 \mathrm{~min}$ was identified as $\alpha$-pinene. The components having retention time of $36.78,38.20$, and $38.93 \mathrm{~min}$ were identified as $\beta$-amyrenone, $\alpha$-amyrenone, and $\alpha$-amyrin, respectively. The chromatographic profile (Figure 5) of the methanol extract of $B$. rivae resin collected 


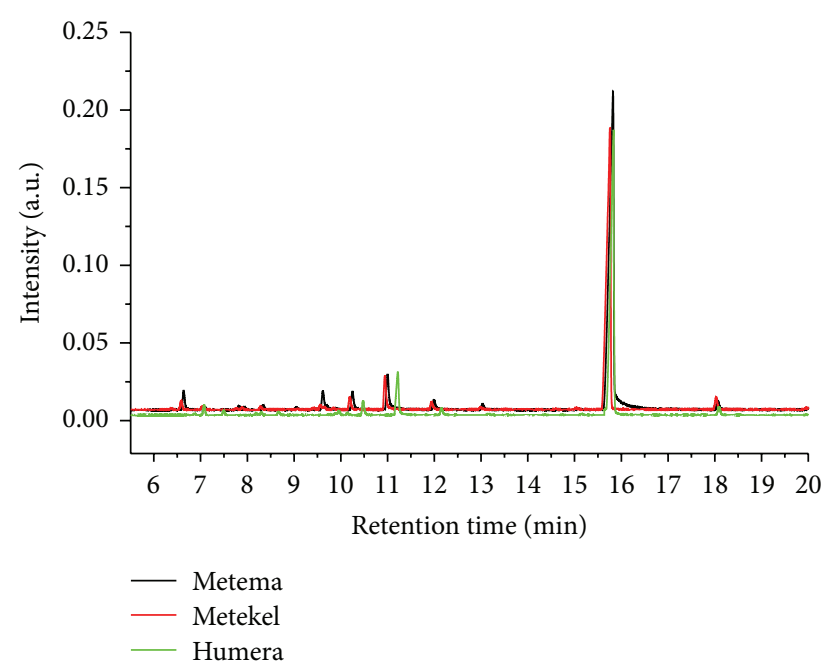

FIGURE 3: Comparison of chromatogram of essential oil of three of B. papyrifera resins.

TABLE 3: Chemical compositions (\%) of essential oils of three of $B$. rivae resins.

\begin{tabular}{|c|c|c|c|c|}
\hline $\begin{array}{l}\text { Retention } \\
\text { time (min) }\end{array}$ & Components & $\begin{array}{c}\text { Dolo Odo } \\
\%\end{array}$ & $\begin{array}{c}\text { Filtu } \\
\%\end{array}$ & $\begin{array}{c}\text { Chereti }^{*} \\
\%\end{array}$ \\
\hline 6.4 & $\alpha$-Thujene & 10.0 & 2.3 & 1.7 \\
\hline 6.7 & $\alpha$-Pinene & 66.2 & 37.3 & 32.5 \\
\hline 7.8 & o-Cymene & 2.6 & 5.6 & 3.0 \\
\hline 9.1 & $\Delta$-3-Carene & 0.7 & 6.7 & 6.2 \\
\hline 9.5 & p-Cymene & 5.7 & 9.8 & 21.1 \\
\hline 9.7 & Limonene & 1.1 & 9.7 & 19.6 \\
\hline 13.4 & $\alpha$-Campholene aldehyde & 1.8 & 1.5 & 1.6 \\
\hline 13.6 & trans-Verbenol & 2.9 & 2.9 & 1.7 \\
\hline
\end{tabular}

${ }^{*}$ Components identified from the essential oil of same sample reported in our previous study [13].

TABLE 4: Chemical compositions (\%) of essential oils of three of B. papyrifera resins.

\begin{tabular}{lcccc}
\hline $\begin{array}{l}\text { Retention } \\
\text { time (min) }\end{array}$ & Components & $\begin{array}{c}\text { Metekel } \\
\%\end{array}$ & $\begin{array}{c}\text { Metema } \\
\%\end{array}$ & $\begin{array}{c}\text { Humera } \\
\%\end{array}$ \\
\hline 6.4 & $\alpha$-Pinene & 0.9 & 2.0 & 2.3 \\
10.4 & Limonene & 1.4 & 2.1 & 3.8 \\
11.1 & n-Octanol & 3.4 & 4.7 & 8.8 \\
12.1 & Linalool & 1.0 & 1.1 & 2.1 \\
15.8 & Octyl acetate & 57.1 & 65.7 & 60.4 \\
18.1 & Geraniol & 1.4 & 0.8 & 2.5 \\
\hline
\end{tabular}

${ }^{*}$ Components identified from the essential oil of same sample reported in our previous study [13].

from Chereti area evidenced the presence of one monoterpene: $\alpha$-pinene and two triterpenoic constituents: $\beta$-amyrin and $\alpha$-amyrin. The components which had retention time of $6.38,37.47$ and $38.13 \mathrm{~min}$ were identified as $\alpha$-pinene, $\beta$ amyrin and $\alpha$-amyrin, respectively.

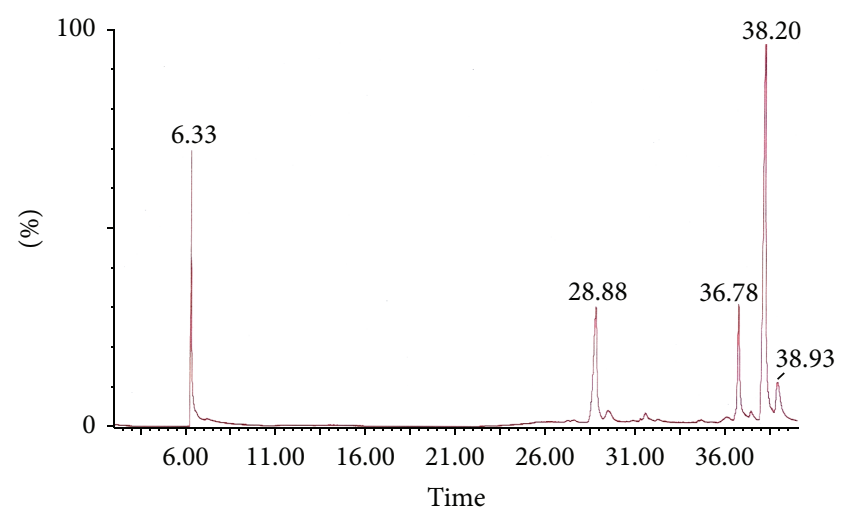

FIGURE 4: Chromatogram of methanol extract of B. neglecta resin of Wachile origin.

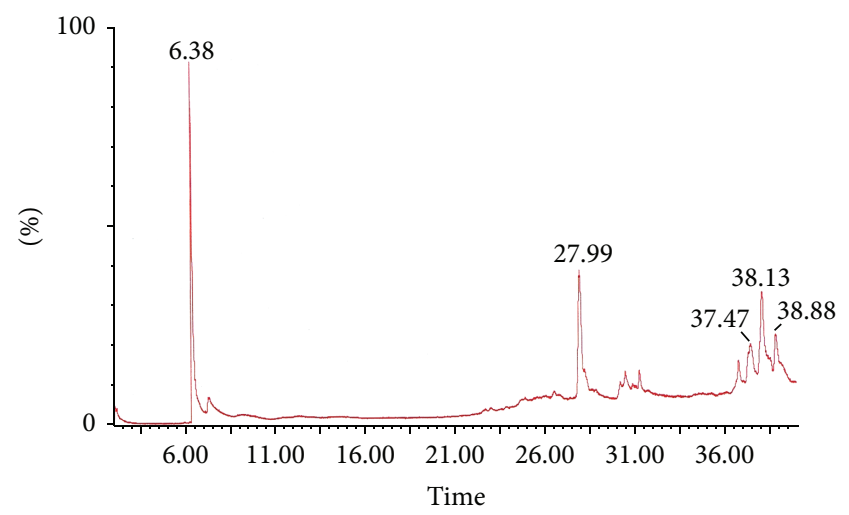

FIGURE 5: Chromatogram of methanol extract of B. rivae resin of Chereti origin.

Another species studied was B. papyrifera, the resin of which was collected from northern part of Ethiopia (Metema, Metekel, and Humera areas). The methanol extract of $B$. papyrifera resin was found to be composing one diterpene and three triterpenes. The chromatogram (Figure 6) of methanol extract of $B$. papyrifera resin collected from Humera area revealed components with retention time of $20.87,24.83,24.95$, and $26.25 \mathrm{~min}$ which were identified as incensyl acetate, $\beta$-amyrenone, $\beta$-amyrin, and $\alpha$ amyrin, respectively. For those, collected from Metekel area, the chromatographic profile (Figure 7) revealed components with retention time of 20.41,21.78, 21.87, 30.47, and $31.28 \mathrm{~min}$ and were recognized as verticilla- $4(20), 7,11$-triene, incensole, incensyl acetate, 24-noroleana-3,12-diene, and 24norursa-3,12-diene, respectively, whereas the chromatogram (Figure 8) of methanol extract of B. papyrifera resin collected from Metema area revealed components with retention time of 20.90 and $26.44 \mathrm{~min}$ and these were identified as incensyl acetate and $\alpha$-boswellic acid, respectively.

3.3. Interpretation of Mass Spectra of the Identified Components. In the present study, the identified components were confirmed by interpretation of their mass spectra (MS). 


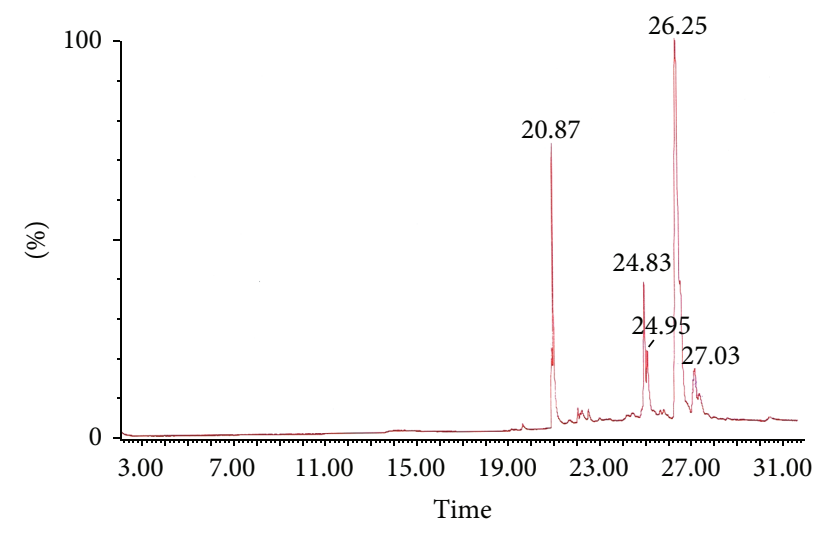

Figure 6: Chromatogram of methanol extract of B. papyrifera resin of Humera origin.

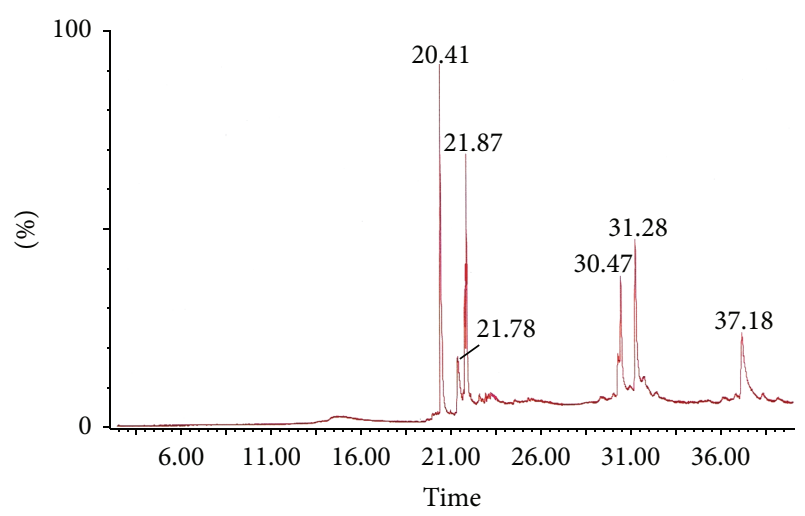

Figure 7: Chromatogram of methanol extract of B. papyrifera resin of Metekel origin.

Some chemical compositions of methanol extract of frankincense samples examined were found to be very similar, and the identified compounds have already been reported from similar and other species of Boswellia as well as in other plants. Most of them are triterpenes which belong to the oleanane or ursane series and are characterized by a base peak at $m / z=218$. Hence, to avoid confusion on interpreting mass spectra of terpenes identified, analytical review on the base peaks, main fragments, and fragmentation patterns of the skeleton of terpenes identified was presented. The fragmentation patterns of pentacyclic triterpenoid compounds having a double bond at position 12 (12-oleanane type and 12-ursane type) show similar fragment at $\mathrm{m} / \mathrm{z}=$ 218 which is formed by Retro-Diels-Alder (RDA) fragment. The MS of 12-ursane type triterpene resembles that of 12oleanene type. The compounds have been identified by their retention time and mass spectral comparison. 12-Ursane and 12-oleanene type pentacyclic triterpenes undergo primarily $\mathrm{RDA}$ fragmentation. The RDA fragment including rings $\mathrm{D}$ and $\mathrm{E}$ of both types of compounds altered only in the position of a single methyl group at C-20. In 12-ursane type triterpenes C-17, C-19, and C-20 were occupied with methyl groups whereas in 12-oleanene types C-20 was occupied with two methyl groups. The retention time is influenced

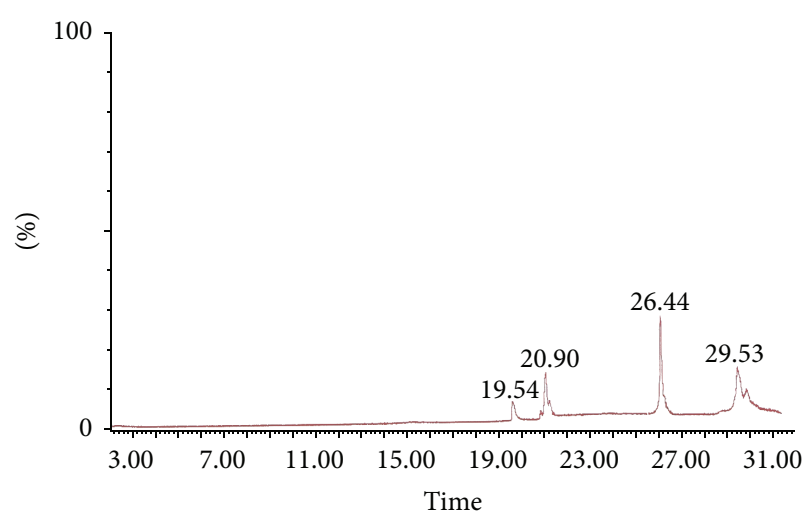

FIGURE 8: Chromatogram of methanol extract of B. papyrifera resin of Metema origin.

by the number and the type of functional groups present and generally increases with increasing molecular weight of triterpenes [17]. Depending on the absolute configuration, $\alpha$-configuration (ursane type) was found to have longer retention time than $\beta$-configuration (oleanane type) due to shift of the $\mathrm{CH}_{3}$ group from an axial conformation at C-20 in oleanane structures to an equatorial conformation at C-19 in ursane type compounds which caused an increase in the planarity of the molecules that related to their retention time [2]. Comparison in their MS between peaks at $m / z=203$ and $m / z=189$ allows making the distinction between oleanane and ursane type triterpenes. But a loss of a methyl group produced the signal at $\mathrm{m} / z=203$ for both compounds. However, the later fragment was more abundant in the mass spectrum of oleanane type than ursane type. This happens because of more stable tertiary carbenium ion formed in oleanane type of triterpenes than the secondary carbenium ion formed in ursane type of triterpenes as a result of methyl cleavage [2]. As reported by Mathe et al. [17], for oleanene derivative, the fragment ion at $m / z=203$ is more intense than the peak at $m / z=189$, while for identical ursane derivatives both peaks have almost similar intensities in their mass spectra.

Accordingly, the two components identified, in this study, as $\beta$-amyrenone and $\alpha$-amyrenone showed molecular ion peaks $\left(\mathrm{M}^{+}\right)$at $m / z=424$ in their mass spectrum which is consistent with molecular formula of $\mathrm{C}_{30} \mathrm{H}_{48} \mathrm{O}$. However, the abundant ions at $m / z 218,203,205,409$, and 189 are typical for the fragmentation of $\beta$-amyrenone and $\alpha$-amyrenone. Both compounds showed similar MS and their mass spectrum shows a typical fragmentation pattern of ursane and oleanane type triterpenes. Finally, identification was made by comparing their retention time and intensity of signal at $\mathrm{m} / z=189$ and $m / z=203$. Therefore, the component which had shorter retention time and more intense peak at $m / z=203$ was assigned as $\beta$-amyrenone and $\alpha$-amyrenone was found to be compound with longer retention time and similar peak signal intensity at $m / z=189$ and 203. Possible fragmentation pattern for $\beta$-amyrenone is presented in Figure 9.

Compounds identified as $\beta$-amyrin and $\alpha$-amyrin produced molecular ion peak signal at $m / z=426$ in their mass 


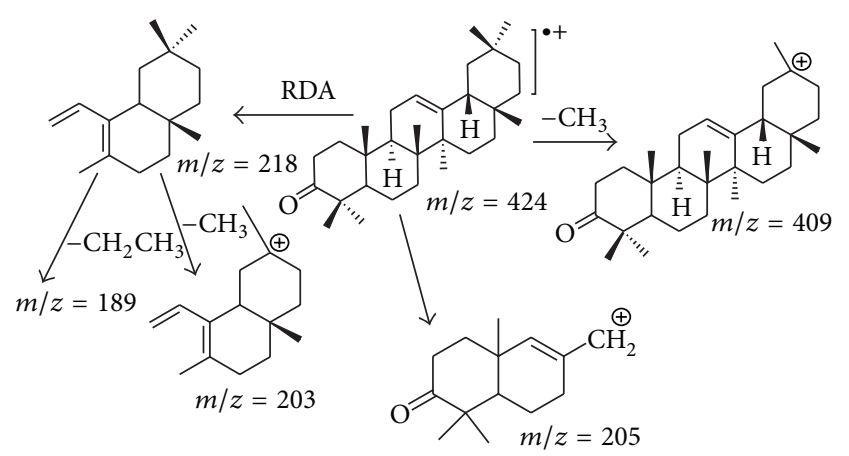

Figure 9: Possible fragmentation patterns for $\beta$-amyrenone.

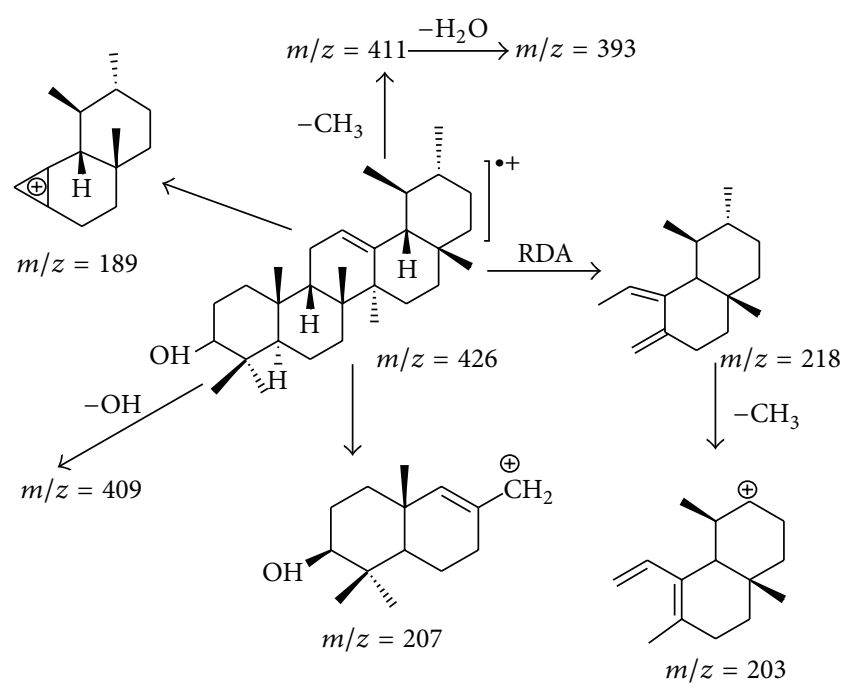

FIGURE 10: Possible fragmentation patterns for $\alpha$-amyrin.

spectrum that corresponded to an elemental composition of $\mathrm{C}_{30} \mathrm{H}_{50} \mathrm{O}$. Similar to that of amyrenone derivative, they produced similar MS. The difference of two in the mass unit indicates exchange of a keto group for a hydroxy group which leads to an increase of molecular weight and polarity. As a consequence, this compound had longer retention time than derivative of amyrenone. $\alpha$ - and $\beta$-Amyrin were differentiated by examination of the relative intensities of the peaks at $m / z=189$ and 203. $\beta$-Amyrin had high intensity peak at $m / z=203$ which is around twice that of $m / z=189$ peak, while $\alpha$-amyrin spectra show similar intensity for both peaks which was consistent with the earlier results [2]. Generally, the $\alpha$-amyrin triterpene possesses a basic skeleton of the ursane type and the $\beta$-amyrin triterpene possesses a basic skeleton of the oleanane type, and the only difference between them is the methyl position in the E-ring. Accordingly, the possible fragmentation pattern for $\alpha$-amyrin is shown in Figure 10.

Two nortriterpenes (24-norursa-3,12-diene and 24noroleana-3,12-diene) identified from resin of B. papyrifera produced molecular ion $\left(\mathrm{M}^{+}\right)$peak signal at $\mathrm{m} / \mathrm{z}=394$ in their mass spectrum that corresponded to an elemental composition of $\mathrm{C}_{29} \mathrm{H}_{46}$. Both compounds showed similar

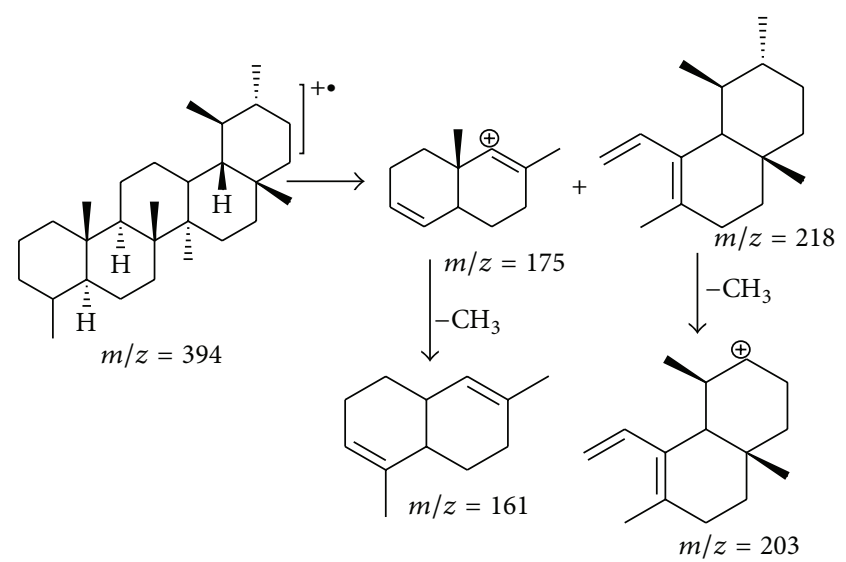

Figure 11: Possible fragmentation patterns for 24-norursa-3,12diene [2].

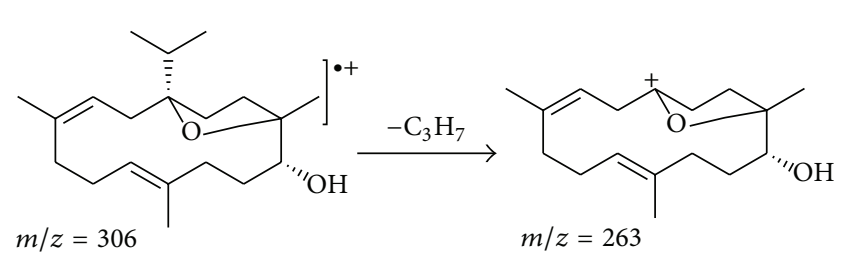

FIGURE 12: Possible fragmentation patterns of incensole.

MS and their mass spectrum showed a similar fragmentation pattern to ursane and oleanane type triterpenes having a double bond at position 12. For both compounds, the RDA reaction revealed a fragment ion signal at $\mathrm{m} / z=218$ and a further methyl cleavage from this fragment formed signal at $m / z=203$. But the intensity of the fragment ion signal at $m / z=203$ produced by 24 -norursa-3,12-diene was found to be greater almost by $50 \%$ than that produced by 24 noroleana-3,12-diene because the former is ursane derivative of the latter. As such, the two nortriterpenes were identified. Possible fragmentation pattern for 24-norursa-3,12-diene is given in Figure 11.

The compound which produced molecular ion peak signal at $\left(\mathrm{M}^{+}\right) \mathrm{m} / z=306$ in its mass spectrum corresponded to an elemental composition of $\mathrm{C}_{20} \mathrm{H}_{34} \mathrm{O}_{2}$. Cleavage of the isopropyl group from molecular ion at $\mathrm{m} / z=306$ produced fragment with an elemental composition of $\mathrm{C}_{17} \mathrm{H}_{27} \mathrm{O}_{2}$ which gave rise to peak at $m / z=263$. This diterpene is found to be incensole. Possible fragmentation pattern for incensole was given in Figure 12.

Another compound identified in this study produced molecular ion peaks signal at $\left(\mathrm{M}^{+}\right) \mathrm{m} / z=348$ in its mass spectrum that corresponded to an elemental composition of $\mathrm{C}_{22} \mathrm{H}_{36} \mathrm{O}_{3}$. There are peaks that appeared in the mass spectra at 245,288 , and 305 . Elimination of the isopropyl group from molecular ion at $\mathrm{m} / z=348$ produced fragment with an elemental composition of $\mathrm{C}_{19} \mathrm{H}_{29} \mathrm{O}_{3}$ which gave rise to peak at $m / z=305$, whereas the fragment ion signal $\mathrm{m} / z=288$ is produced by cleavage of acetic acid group from molecular ion $\left(\mathrm{M}^{+}\right)$. Fragment ion peak signal at $m / z=245$ could be produced by loss of an isopropyl group from $\mathrm{m} / z=288$. 


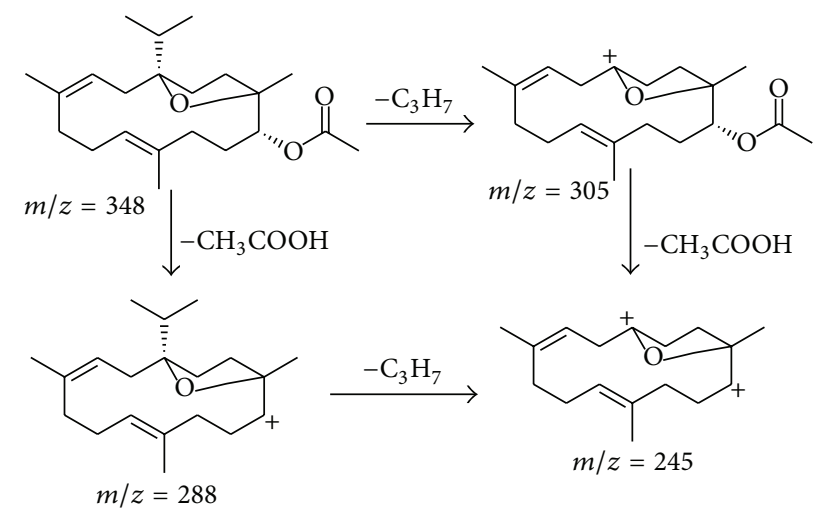

FIgURE 13: Possible fragmentation patterns for incensyl acetate [2].

This compound was identified as incensyl acetate. Possible fragmentation pattern for incensyl acetate was presented in Figure 13.

Another pentacyclic triterpene identified from resin of $B$. papyrifera produced molecular ion peak signal at $\left(\mathrm{M}^{+}\right) \mathrm{m} / z=$ 456 in its mass spectrum that corresponded to an elemental composition of $\mathrm{C}_{30} \mathrm{H}_{48} \mathrm{O}_{3}$. When methyl group is lost from molecular ion peak signal $(m / z=456)$ fragment with an elemental composition of $\mathrm{C}_{29} \mathrm{H}_{45} \mathrm{O}_{3}$ is produced which gave rise to peak at $m / z=441$. The RDA reaction produced peak signal at $m / z=218$ which produces peak signal at $m / z=203$ by loss of methyl group. These fragmentations hold true for both $\beta$-boswellic acid and $\alpha$-boswellic acid. However, the fragment at $m / z=203$ was more abundant in the mass spectrum of $\alpha$-boswellic acid than $\beta$-boswellic acid due to the more stable ion formed from $\alpha$-boswellic acid [2]. Possible fragmentation pattern for $\alpha$-boswellic acid was presented in Figure 14.

Another diterpene was also identified from methanol extract of B. papyrifera by GC-MS. The compound produced molecular ion $\left(\mathrm{M}^{+}\right) \mathrm{m} / z=272$ in its mass spectrum that corresponded to an elemental composition of $\mathrm{C}_{20} \mathrm{H}_{32}$. The fragmentation mechanism shows initially cleavage of allyl methyl group from the molecular ion which further undergoes RDA reaction in the cyclohexene ring to produce peak signal at $m / z=257$ representing the base peak in its mass spectra. Accordingly, possible fragmentation pattern for verticilla-4(20),7,11-triene was presented in Figure 15.

\subsection{Comparison of Chemical Compositions of the Three} Boswellia Species. As the concern of this study was comparative chemical investigation on resins of three different Boswellia species, the essential oil and methanol extract of $B$. papyrifera, B. neglecta, and B. rivae resin were analysed by GC and GC-MS. This led to the identification of the chemotaxonomical markers for each species. The GC investigations of the essential oils of $B$. papyrifera, $B$. neglecta, and $B$. rivae resin showed that these oils were composed of a number of monoterpenoic constituents. But investigation on the methanol extract of three Boswellia species showed that they are composed of diterpenes and triterpenes. However,
B. papyrifera was identifiable by its diterpenoic and nortriterpenoic constituents.

The essential oil of $B$. papyrifera was found to be dominated by octyl acetate (57.1-65.7\%) followed by high content of n-octanol (3.4-8.8\%), linalool (1.0-2.1\%), and others monoterpenes. In our previous study, preliminary data obtained by investigation on resin samples of three types of Boswellia species collected from very limited area revealed similar results with the current study [13]. In the present study, except for their composition, similar constituents were identified from the essential oils of the three Boswellia species [13]. Surprisingly, similar components with identical percent composition were obtained for samples collected from the same areas with samples collected for preliminary investigation in our previous study. The result obtained in this study is also consistent with result obtained by other authors: $64.6 \%$ according to Hamm et al. [18], 63.6\% by Camarda et al. [20], and $56 \%$ by Dekebo et al. [15]. Assefa et al. [21] also reported octyl acetate as major component of B. papyrifera. In addition, incensyl acetate was found to be dominant component in methanol extract of resins of B. papyrifera. B. papyrifera was the only species that was found to contain octyl acetate, n-octanol, linalool, and geraniol and they are chemotaxonomical markers for this species. Octyl acetate and n-octanol were reported as they are responsible for acrid odour of the resin [2]. Oils from both $B$. neglecta and B. rivae were predominantly composed of $\alpha$-pinene. B. neglecta was found to be rich in $\alpha$-pinene (32.6-50.7\%) followed by terpinen-4-ol (17.5-29.9\%) and $\alpha$ thujene (12.7-16.5\%). Similarly, B. rivae was predominated by $\alpha$-pinene (32.5-66.2\%) followed by p-cymene (5.7-21.1\%) and limonene (1.1-19.6\%).

The methanol extract of the Boswellia species resin samples had considerable importance because the resin portion (di-and tri-terpenes) of frankincense is alcohol soluble. The boswellic acid was identified in frankincense samples as pentacyclic triterpenoic acids which follow the ursane and oleanane basic skeletons. The presence of diterpenoic (incensole, incensyl acetate, and verticilla-4(20),7,11-triene), nortriterpenes (24-noroleana-3,12-diene and 24-norursa-3,12diene), and pentacyclic triterpene acid ( $\alpha$-boswellic acid) constituents turned out to be a chemotaxonomical marker for B. papyrifera. Methanol extract of B. rivae and B. neglecta was also found to contain monoterpene ( $\alpha$-pinene) and triterpenes, namely, $\beta$-amyrin, $\alpha$-amyrin, $\beta$-amyrenone, and $\alpha$ amyrenone. Most importantly, two monoterpenes (p-cymene and $\alpha$-thujene) were found to be characteristic for the $B$. rivae and $B$. neglecta. Terpinen-4-ol and verbenone were two constituents identified as chemotaxonomical markers of essential oil of B. neglecta, whereas transverbenol and $\alpha$-campholene aldehyde are two monoterpenes which were identified only from essential oil of $B$. rivae and hence are characteristic for this species.

\section{Conclusion}

In this study, essential oils and methanol extract of B. papyrifera, B. neglecta, and B. rivae were investigated. 


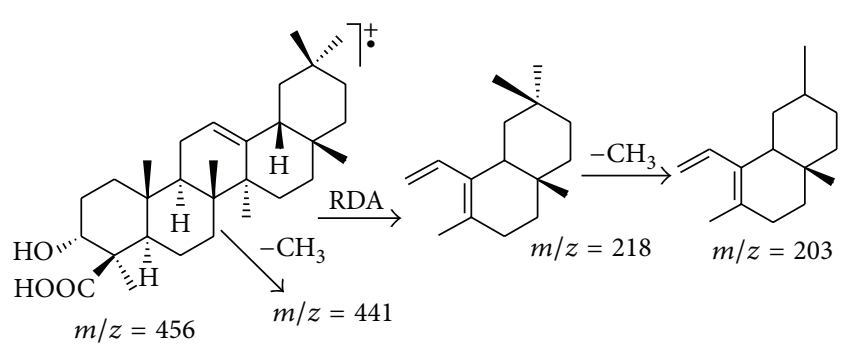

FIgURE 14: Possible fragmentation patterns of $\alpha$-boswellic acid.

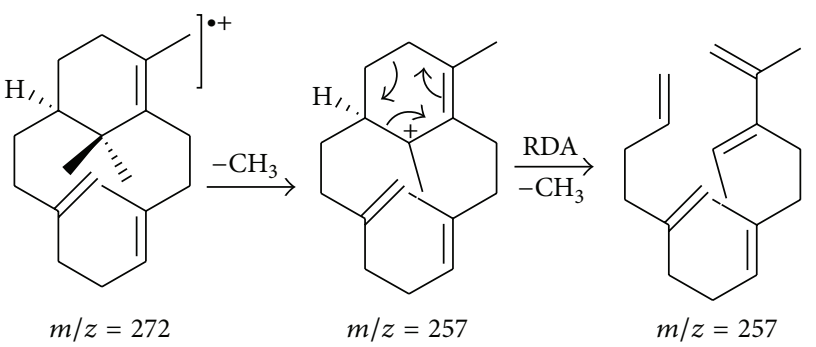

Figure 15: Possible fragmentation mechanism for verticilla-4(20), 7,11-triene [2].

The investigations which were carried out by GC and GC-MS led to the identification of the chemotaxonomical markers for each species. Some differences in their chemical constituents were observed and are chemotaxonomical markers for each species.

The chemical investigations performed on three Boswellia species show that they consist of high number of monoterpenoic constituents and their methanol extract is composed of diterpenes and triterpenes. The presence of octyl acetate, $n$ octanol, and incensyl acetate provided an immediate recognition of $B$. papyrifera from the other two species. But still it is difficult to conclude that there is profound chemical quality variation between $B$. papyrifera and the other two species (B. neglecta and $B$. rivae) that makes them not of export standard even though further study is required. However, a further investigation is crucial especially to extract some chemical information regarding the constituents which might be reasonable for their difference in color and physical appearance.

\section{Conflict of Interests}

The authors declare that there is no conflict of interests regarding the publication of this paper.

\section{Acknowledgments}

The authors would like to thank Center for International Forestry Research, Ethiopia Office Addis Ababa; the Central Laboratory of the Haramaya University; the Department of Chemistry of Addis Ababa University; Department of Chemistry of Indian Institute of Technology; and the Ethiopian
Natural Gum and Marketing Enterprise for their collaborations during the research work that led to the production of this paper. Most of the expenses of this research work were funded by the Austrian Development Agency through CIFOR's Community Forestry Project in Ethiopia (Project no. 2008/03). The authors are thankful to the people and Government of Austria.

\section{References}

[1] K. Vollesen, "Burseraceae," in Flora of Ethiopia, I. Edwards and S. Hedbergand, Eds., vol. 3, pp. 442-447, National Herbarium, Addis Ababa University, Addis Ababa, Ethiopia, 1989.

[2] S. Basar, Phytochemical investigations on Boswellia species [Ph.D. thesis], University of Hamburg, Hamburg, Germany, 2005.

[3] A. Al-Harrasi and S. Al-Saidi, "Phytochemical analysis of the essential oil from botanically certified oleogum resin of Boswellia sacra (Omani luban)," Molecules, vol. 13, no. 9, pp. 2181-2189, 2008.

[4] R. A. A. Mothana, S. S. Hasson, W. Schultze, A. Mowitz, and U. Lindequist, "Phytochemical composition and in vitro antimicrobial and antioxidant activities of essential oils of three endemic Soqotraen Boswellia species," Food Chemistry, vol. 126, no. 3, pp. 1149-1154, 2011.

[5] H. Safayhi, E. R. Sailer, and H. P. T. Ammon, "5-Lipoxygenase inhibition by acetyl-11-keto- $\beta$-boswellic acid (AKBA) by a novel mechanism," Phytomedicine, vol. 3, no. 1, pp. 71-72, 1996.

[6] S. M. Abdel Wahab, E. A. Aboutabl, and S. M. El-Zalabani, "The essential oil of olibanum," Planta Medica, vol. 53, no. 4, pp. 382384, 1987.

[7] A. Sharma, S. Chhikara, S. N. Ghodekar et al., "Phytochemical and pharmacological investigations on Boswellia serrata," Pharmacognosy Reviews, vol. 3, no. 5, pp. 206-215, 2009.

[8] A. O. Tucker, "Frankincense and myrrh," Economic Botany, vol. 40, no. 4, pp. 425-433, 1986.

[9] J. Stenhouse, "Zusammensetzung des Elemi- und Olibanumöls," Liebigs Annalen der Chemie, vol. 35, pp. 304-306, 1840.

[10] A. Dekebo, M. Zewdu, and E. Dagne, "Volatile oils of frankincense from Boswellia papyrifera," Bulletin of the Chemical Society of Ethiopia, vol. 13, no. 1, pp. 93-96, 1999.

[11] Girmay Fitwi, "The status of gum Arabic and Resins in Ethiopia," Report of the Meeting of the Network for Natural Gum and Resins in Africa (NGARA), Network for Natural Gum and Resins in Africa, Nairobi, Kenya, 2000.

[12] Mulugeta Lemenih and Demel Teketay, "Frankincense and myrrh resources of Ethiopia: medicinal and industrial uses," Ethiopian Journal of Science, vol. 26, no. 2, pp. 161-172, 2005.

[13] M. Assefa, B. Shimelis, H. Kassa et al., "Chemical investigations on frankincense from Boswellia trees to improve production, handling and grading practices for the export market in Ethiopia," Global Journal of Pure \& Applied Science and Technology, vol. 2, pp. 15-30, 2012.

[14] J. H. Y. Vilegas, F. M. Lanças, W. Vilegas, and G. L. Pozetti, "Further triterpenes, steroids and furocoumarins from Brazilian medicinal plants of Dorstenia genus (Moraceae)," Journal of the Brazilian Chemical Society, vol. 8, no. 5, pp. 529-535, 1997.

[15] A. Dekebo, E. Dagne, O. R. Gautun, and A. J. Aasen, “Triterpenes from the resin of Boswellia neglecta," Bulletin of the Chemical Society of Ethiopia, vol. 16, no. 1, pp. 87-90, 2002. 
[16] F. A. Badria, B. R. Mikhaeil, G. T. Maatooq, and M. M. A. Amer, "Immunomodulatory triterpenoids from the oleogum resin of Boswellia carterii birdwood," Zeitschrit fur Naturforschung C, vol. 58, no. 7-8, pp. 505-516, 2003.

[17] C. Mathe, G. Culioli, P. Archier, and C. Vieillescazes, "Characterization of archaeological frankincense by gas chromatography-mass spectrometry," Journal of Chromatography A, vol. 1023, no. 2, pp. 277-285, 2004.

[18] S. Hamm, J. Bleton, J. Connan, and A. Tchapla, "A chemical investigation by headspace SPME and GC-MS of volatile and semi-volatile terpenes in various olibanum samples," Phytochemistry, vol. 66, no. 12, pp. 1499-1514, 2005.

[19] S. G. Leitão, D. R. De Oliveira, V. Sülsen et al., "Analysis of the chemical composition of the essential oils extracted from Lippia lacunosa Mart. \& Schauer and Lippia rotundifolia Cham. (Verbenaceae) by gas chromatography and gas chromatographymass spectrometry," Journal of the Brazilian Chemical Society, vol. 19, no. 7, pp. S1-S28, 2008.

[20] L. Camarda, T. Dayton, V. Di Stefano, R. Pitonzo, and D. Schillaci, "Chemical composition and antimicrobial activity of some oleogum resin essential oils from Boswellia spp. (Burseraceae)," Annali di Chimica, vol. 97, no. 9, pp. 837-844, 2007.

[21] M. Assefa, A. Dekebo, H. Kassa, A. Habtu, G. Fitwi, and M. Redi-Abshiro, "Biophysical and chemical investigations of frankincense of Boswellia papyrifera from North and Northwestern Ethiopia," Journal of Chemical and Pharmaceutical Research, vol. 4, no. 2, pp. 1074-1089, 2012. 

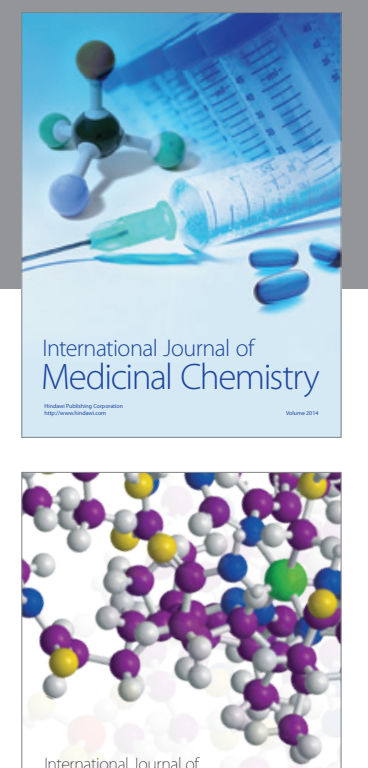

\section{Carbohydrate} Chemistry

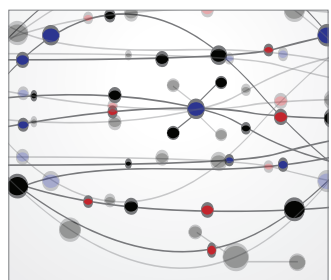

The Scientific World Journal
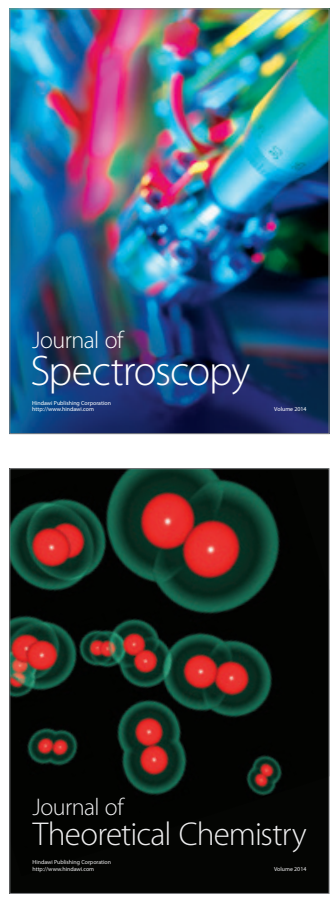
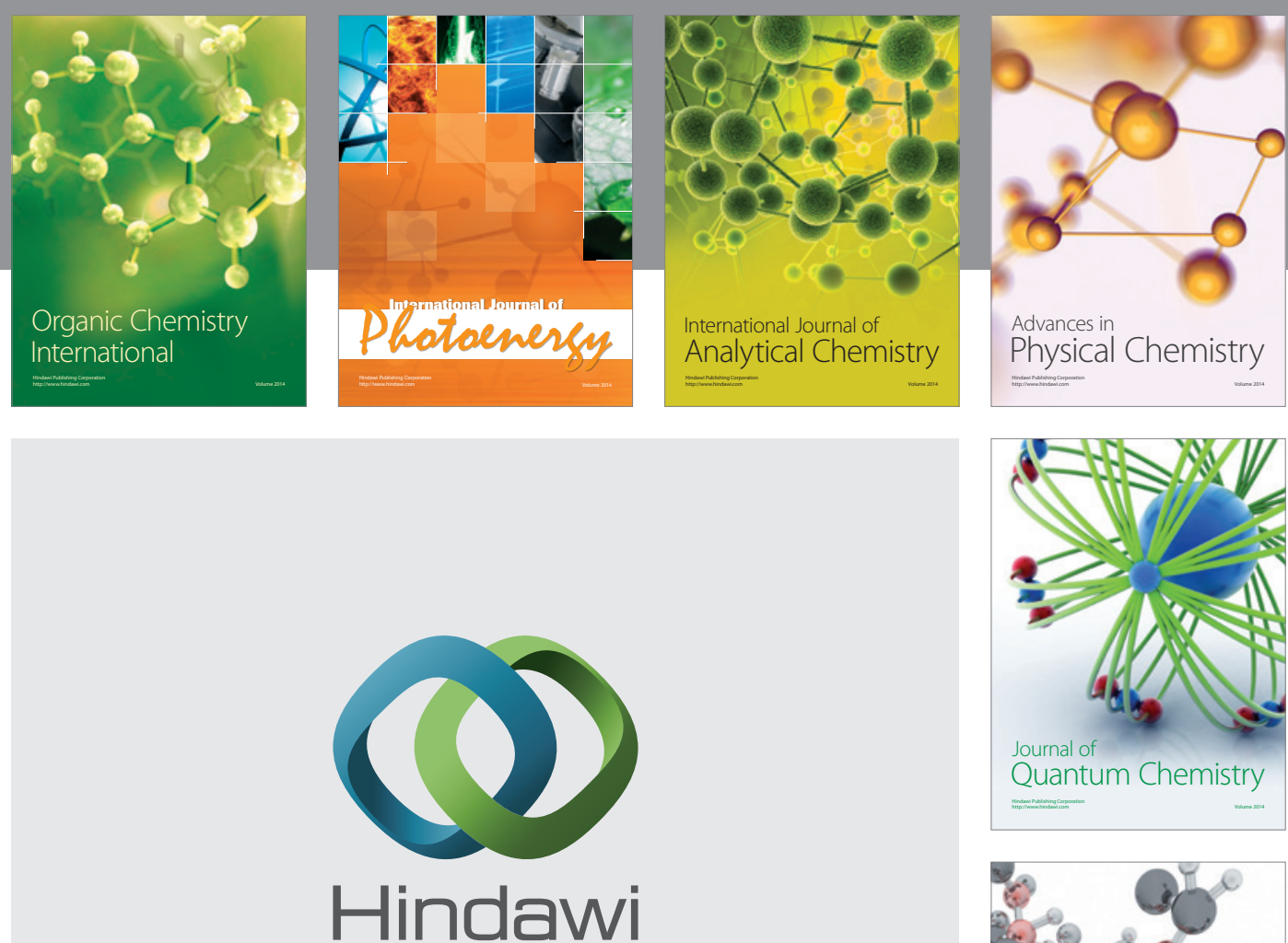

Submit your manuscripts at

http://www.hindawi.com

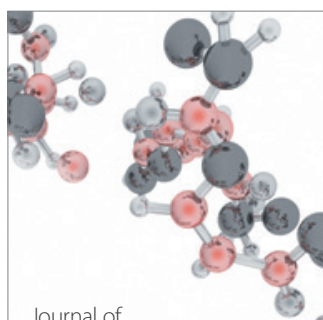

Analytical Methods

in Chemistry

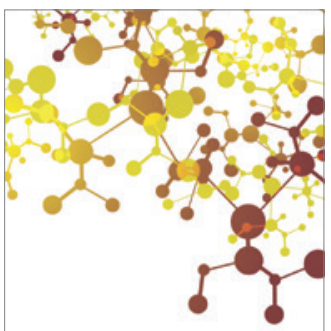

Journal of

Applied Chemistry

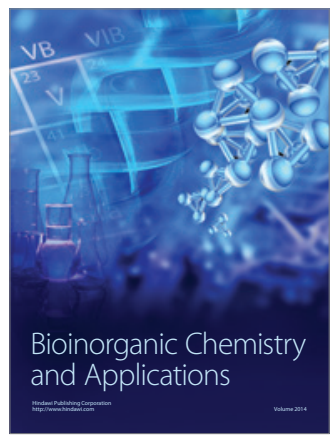

Inorganic Chemistry
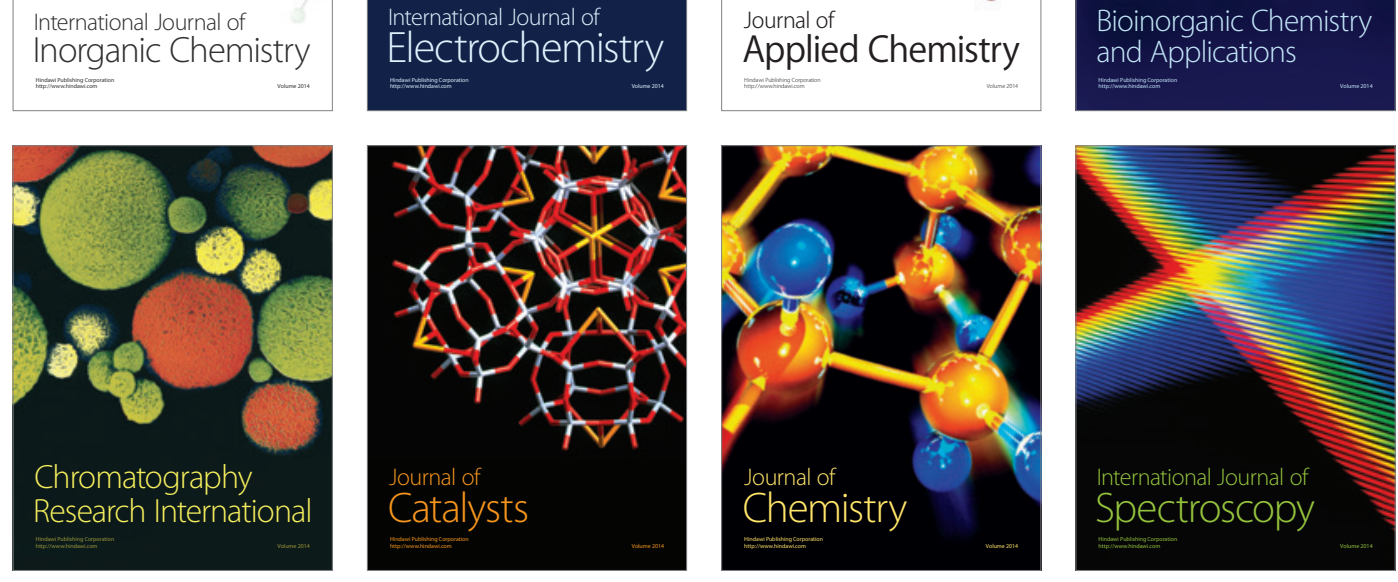